\title{
PERSEPSI TATO PADA CHANNEL YOUTUBE PODCAST DEDDY CORBUZIER BERSAMA HENDRIC SHINIGAMI TAYANGAN
} JANUARI 2020

\author{
Muhammad Misbahul Huda \\ Fakultas Dakwah dan Komunikasi \\ Universitas Islam Negeri Sunan Kalijaga Yogyakarta \\ hudamisbahul100297@gmail.com
}

\begin{abstract}
The focus of this research is on someone's perception of tattoos. The perception was taken on Deddy Corbuzier's youtube podcast channel "Raja Tattoo I Invite Debate". This type of research uses research library research with Roland Barthes semiotic analysis, namely denotation, connotation, and myth. The technique oforganizing data uses the documentation method. Hendric Shinigami, Deddy Corbuzier, and citizens or netizens in an effort to change the perception of the wider community in seeing tattoos. The results of his research are 1) Semiotics Roland Barthes discovered the meaning of denotation, connotation, and myth. The meaning of denotation: a tattoo is a picture (painting) on a person's body. Meaning of connotation: tattoos are identical to people who are branded, jerks, drug users, and other negative sides. While the myth: tattoos and negative images no one expected. 2) Hendric Shinigami, Deddy Corbuzier, and citizens or netizens are aligned in an effort to change the perception of the general public regarding tattoos that are not always negative.
\end{abstract}

Keywords : Perception, Tattoo, Semiotics Analysis, Roland Barthes

\begin{abstract}
Abstrak
Fokus penelitian ini pada persepsi seseorang tentang tato. Perpsepsi tersebut diambil pada channel podcast youtube Deddy Corbuzier versi "Raja Tattoo Gue Ajak Debat". Jenis penelitian ini menggunakan penelitian library research dengan analisis semiotika Roland Barthes, yaitu denotasi, konotasi, dan mitos. Teknik pengumpulan data menggunakan metode dokumentasi. Penelitian ini bertujuan untuk mengetahui persepsi tato menurut Hendric Shinigami, Deddy Corbuzier, dan warganet atau netizen dalam upaya mengubah persepsi masyarakat luas dalam melihat tato. Hasil penelitiannya yaitu 1) Semiotika Roland Barthes menemukan makna denotasi, makna konotasi, dan mitos. Makna denotasi: tato adalah gambar (lukisan) pada tubuh seseorang. Makna konotasi: tato identik dengan orang yang brandal, brengsek, pengguna narkoba, dan sisi negatif
\end{abstract}


lainnya. Sedangkan mitos: tato dan image negatif tidak ada hubungannya. 2) Hendric Shinigami, Deddy Corbuzier, dan warganet atau netizen selaras dalam upaya untuk mengubah persepsi masyarakat luas terkait tato yang tidak selalu dipandang negatif.

Kata Kunci: Persepsi, Tato, Analisis Semiotika, Roland Barthes

\section{A. PENDAHULUAN}

Pada kehidupan masyarakat modern, semua tindakan yang berkenaan dengan tubuh adalah bagian dari pertunjukan. Tubuh adalah bagian yang paling tampak, sehingga dijadikan simbol nyata bagi setiap jiwa dalam proses penyampaian pesan. Akibat dari simbolisasi yang dipaparkan oleh subjek tersebut, maka tubuh menjadi multi-interpretatif bagi objek yang menafsirkannya (Olong, 2006: 8). Mulai dari gaya pakaian, dandanan rambut, bahkan segala aksesoris yang menempel adalah bagian dari cerminan diri atau identitas diri seseorang (Adhitiya Nugraha, 2016).

Salah satu bentuk identitas seseorang yang sangat kentara adalah penggunaan tato dalam tubuh. Tato adalah sebuah simbol/ tanda. Menurut Geertz, simbol adalah ajang, tempat, atau wahana yang memuat sesuatu nilai yang bermakna (meaning). Dari simbol tersebut, kebudayaan baru pun muncul, sehingga dapat mempengaruhi cara-cara berfikir individu ataupun komunal dalam perilakunya (Olong, 2006). Mengacu pada sistem semiotika Roland Barthes, simbol/ tanda adalah perangkat yang kita pakai dalam upaya mencari jalan di dunia.

Dalam istilah semiotika Barthes, semiologi pada dasarnya hendak mempelajari bagaimana kemanusiaan (humanity) dan memaknai hal-hal (to signfy things). Dalam lingkup berkomunikasi (to communicate) kedua hal tersebut tentu tidak akan dapat bercampur, sebab pada setiap perangkat yang dibawa oleh manusia (human) mempunyai beragam makna, mulai dari subjek (manusia-dirinya) atau objek (manusia-yang melihat). Maka dari itu, dikira perlu untuk mengkonstitusi sistem secara terstruktur dari tanda yang dibawa 'manusia' itu sendiri.

Dengan adanya hal itu, dalam posisi subjek maupun objek 'manusia', baiknya mengenal manusia atau seseorang secara mendalam terlebih dahulu, baru memunculkan penilaian/persepsi terhadap seseorang tersebut. Baik orang tersebut bertato, ataupun tidak. Karena jika menilai/berprasangka kepada seseorang tanpa mengenal lebih jauh terlebih dahulu, kemungkinan besar akan terjadi kesalahan komunikasi (miss communication). Dalam Islam kebiasaan berprasangka kepada orang lain sudah diatur dalam al-Qur-an, Firman Allah:

"Hai orang-orang beriman, jauhilah kebanyakan dari prasangka, karena sesungguhnya sebagian tindakan prasangka adalah dosa dan janganlah kamu mencari-cari kesalahan orang lain". (QS Al-Hujurat: 12)

Kemudian dalam sebuah al-Hadits juga disebutkan tentang prasangka, karena sejatinya prasangka adalah keburukan. Maka dari itu, Rasulullah SAW bersabda:

"Berhati-hatilah kalian dari tindakan berprasangka buruk, karena prasangka buruk adalah sedusta-dustanya ucapan. Janganlah kalian mencari berita kejelekan orang lain, saling memata-matai, saling

ISSN : 2085-3521, E-ISSN : 2548-9054 
membelakangi, dan saling membenci. Jadilah kalian hamba-hamba Allah yang bersaudara". (Diriwayatkan oleh AlBukhari Hadits no. 6064 dan Muslim Hadits no. 2563)

Dari kedua sumber berupa alQur'an dan al-Hadits tersebut, setidaknya memberi sebuah pemahaman bahwasanya jangan terburu-buru dalam memunculkan prasangka atau persepsi tentang orang, baik orang yang bertato atapun tidak, lebihlebih mengira bahwa orang bertato selalu di 'jugde-negative'. Akan lebih bijaksana ketika mengenal dulu orang yang bertato tersebut, setelah mengenal orang tersebut, baru memunculkan prasangka/persepsi.

Berbicara mengenai sejarah 'tato' salah satu tokoh yang bernama Lemma mengatakan bahwa, pada akhir 1970-an dan awal 1980-an tato menjadi pernyataan fashion yang dipopulerkan oleh kelompok punk rock. Saat ini, tato adalah aksesoris fashion kelas menengah yang dipakai pada peragaan busana internasional.

Karena 'tato' pada tubuh seseorang pasti mempunyai makna tersendiri bagi pemiliknya, dan yang lebih penting adalah simbol tato pada tubuh tidak bisa menentukan sifat seseorang. Dalam hal ini, teori Roland Barthes diterapkan, sebab teori Barthes bersifat menyeluruh, dan dapat menghubungkan unsur suatu tanda secara logis, serta deskripsi struktural dari semua sistem penandaan dan pertandaan (Sobur, 2016:156).

Maka dari itu analisis semiotika Roland Barthes lebih fleksibel digunakan dalam meneliti visual seperti halnya film, iklan, ataupun konten video yuotube.
Dan analisis ini juga bersifat pragmatik, yakni analisis semiotika yang mempelajari hubungan diantara tanda-tanda dengan penggunanya (Budiman, 2011:56). Seperti inilah yang diinginkan oleh peneliti, di mana peneliti melihat hubungan antara suatu tanda dengan objeknya, sehingga dapat mengetahui persepsi tato dari sisi Hendric Shinigami, Deddy Corbuzier, dan warganet atau nitizen pada channel youtube podcast Deddy Corbuzier.

Youtube merupakan salah satu bentuk media berbasis video yang mulai naik daun sejak 5 tahun yang lalu dan memiliki lebih dari satu miliar pengguna jika dilihat dari statistik situsnya (David, Sondakh, dan Harilama, 2017:1). Maka dari itu media youtube telah menjadi salah satu media favorit untuk saat ini. Banyak konten creator yang menggunakan youtube sebagai tempat untuk menuangkan ide serta kreativitasnya (Shera Aske dan Sukendro, 2018). Salah satu channel youtube podcast yang sedang hangat saat ini yaitu akun milik Deddy Corbuzier dengan pembahasan mengenai tato dan menghadirkan sosok orang bertato dan pembuat tato terkenal Hendric Shinigami sebagai narasumbernya (Lystiarini dan Nafarin, 2020).

Secara sederhana podcast diartikan sebagai materi yang tersedia di internet yang dapat secara otomatis dipindahkan ke komputer atau media pemutar portable baik secara gratis atau berlangganan (Fadilah, Yudhapramesti, dan Aristi, 2017). Melalui channel youtube podcast Deddy Corbuzier, baik Deddy maupun Hendric ingin memberi pemahaman masyarakat luas tentang tato.

Pemahaman tersebut bertujuan agar masyarakat tidak selalu mempersepsikan 
tato pada sisi negatif. Sebab, tato pada tubuh seseorang tidak akan bisa menggambarkan karakter seseorang, terlebih langsung digolongkan pada sosok penjahat atau kriminal. Akan lebih baik jika memandang sesuatu 'tato' dari sisi positif. Misalnya tato dimaknai sebagai sebuah karya seni. Disebut karya seni sebab ada sebuah kegiatan di mana pembuat tato mendesain atau menggambar pola dalam tubuh seseorang dan berbagai perlombaan tentang tato yang akan sedikit demi sedikit menggeser persepsi negatif masyarakat (Umbara, Suciptawati, dan Nilakusumawati, 2018:1).

Tato tidak hanya dimaknai sebagai karya seni, tato juga digunakan sebagai simbol atau tanda pada suku-suku tertentu. Bangsa Yunani menggunakan tato sebagai tanda bagi badan intelejen saat perang. Bangsa Romawi membuat tanda pada golongan-golongan budak. Dari Indonesia pada suku Dayak penggunaan tato dimaknai sebagai identitas (Leonardus Ristiardi Noviyanto, 2013:3).

Berdasarkan pemaparan di atas, peneliti tertarik untuk mengetahui apa sajakah denotasi, konotasi, dan mitos mengenai persepsi tato Hendric Shinigami selaku orang bertato dan pembuat/pekerja tato pada konten youtube Deddy Corbuzier versi “Raja Tatto Gue Ajak Debat” dengan menggunakan teori semiotika dari Roland Barthes.

\section{B. METODOLOGI PENELITIAN}

Jenis penelitian yang digunakan oleh peneliti adalah jenis penelitian library research. Penelitian library research adalah jenis penilitian yang menggunakan buku, majalah dokumen, jurnal, karya tulis, internet, dan lain sebagainya untuk mendapatkan informasi yang terkait dengan penelitian yang diteliti (Abdul Rahman, 2005: 63). Peneliti juga menggunakan pendekatan analisis semiotika model Roland Barthes, dengan mencari tanda/simbol dengan menempuh tiga cara, yakni denotasi, konotasi, dan mitos dalam tiga persepsi tentang tato, baik Hendric Shinigami, Deddy Corbuzier, dan warganet/netizen pada konten youtube Deddy Corbuzier versi "Raja Tatto Gue Ajak Debat".

Teknik pengumpulan menggunakan metode dokumentasi. Metode dokumentasi yakni metode menganalisis dokumendokumen yang dibuat oleh subjek sendiri atau orang lain, berupa catatan-catatan, gambar, ataupun karya orang lain. Teknik dokumentasi yang digunakan peneliti untuk mengetahui makna tanda/simbol berupa denotasi, konotasi, dan mitos dalam tiga persepsi tato, Hendric Shinigami yang berperan sebagai orang yang bertato atau pembuat/pekerja tato, Deddy Corbuzier berperan sebagai host sekaligus pemilik konten, dan terakhir warganet/netizen yang turut memberi tulisan "persepsi masingmasing" pada kolom komentar pada konten youtube Deddy Corbuzier versi “Raja Tatto Gue Ajak Debat". Dalam hal tersebut, langkah-langkah yang diambil oleh peneliti sebagai berikut: (a) Mengidentifikasi video konten youtube Deddy Corbuzier versi "Raja Tatto Gue Ajak Debat". (b) Memahami dan mengamati setiap obrolan yang dilakukan oleh Deddy Corbuzier dan Hendric Shinigami, serta komentar warganet/netizen sambil mencari persepsi tentang tato. (c) Kemudian menganalisis

ISSN : 2085-3521, E-ISSN : 2548-9054 
dari bagian 'menit/detik' di setiap obrolan yang berkenaan dengan persepsi terkait tato atau orang bertato, dilanjutkan dengan menyajikan bentuk tabel dan cuplikan bagian yang dimaksud, disertai narasi untuk menjelaskan cuplikan tersebut.

\section{HASIL DAN PEMBAHASAN}

\section{Semiotika Roland Barthes}

Kajian semiotika sampai sekarang terbagi menjadi dua, yakni semiotika komunikasi dan semiotika signifikasi. Semiotika komunikasi menekankan pada teoritentang produksi yang mengasumsikan enam faktor dalam proses komunikasi, yakni pengirim, penerima kode, pesan, saluran komunikasi, dan acuan. Sedangkan pada semiotika signifikasi tidak dipersoalkan adanya tujuan berkomunikasi. Sehingga yang diutamakan adalah pemahaman tanda dari proses kognisinya oleh penerima tanda itu sendiri (Alex Sobur, 2016: 15).

Semiotika adalah ilmu yang mempelajari berbagai tanda. Tanda-tanda sendiri adalah basis daripada komunikasi. Dengan kata lain, manusia dapat berkomunikasi dengan sesamanya ketika memahami perantara tanda (Alex Sobur, 2016: 15). Menurut Zoest, segala sesuatu yang dapat diamati atau dibuat teramati disebut dengan tanda. Adanya peristiwa atau tidak, struktur yang ditemukan dalam sesuatu, atau kebiasaan semua ini dapat disebut dengan tanda (Anggraini, 2018: 17).

Penanda merupakan sesuatu yang memiliki wujud dan dapat di-indra. Ia terletak pada tingkatan ungkapan. Penanda adalah hal yang memiliki fisik seperti halnya bunyi, huruf, warna, gambar, video, dan lain sebagainya. Sedangkan petanda terletak pada tingkatan isi atau gagasan dari penanda, sehingga ketika keduanya dihubungkan, maka akan melahirkan sebuah makna.

Roland Barthes dikenal salah seorang pemikir strukturalis yang mempraktikkan model linguistik dan semiologi Saussure. Ia juga intelektual dan kritikus sastra Prancis yang ternama; eksponen penerapan strukturalisme dan semiotika pada studi sastra (Alex Sobur, 2016: 15). Barthes menjadi tokoh yang identik dengan kajian semiotik. Pemikiran Barthes banyak digunakan dalam berbagai penelitian. Konsep pemikiran Roland Barthes yang terkenal adalah konsep mythologies atau mitos.

Sebagai penerus dari pemikiran Saussure, Roland Barthes menekankan interaksi antara teks dengan pengalaman personal dan kultural penggunanya, interaksi antara konvensi dalam teks dengan konvensi yang dialami dan diharapkan oleh penggunanya (Kriyanto, 2007: 268). Semiotika Barthes menjelaskan definisi signifikasi dua tahap (two order of signification), yakni denotasi dan konotasi.

Konsep ini merupakan penyempurnaan dari semiologi Saussure yang berhenti pada penandaan dalam tataran denotatif. Berikut ini adalah konsep makna denotasi dan konotasi Barthes (Sobur, 2013: 67-70).

Pertama, makna denotasi merupakan sistem signifikasi tingkat pertama dan dinamaknai secara harfiah sebagai makna sebenarnya. Kedua, makna konotasi merupakan makna yang tidak sekedar tambahan dari tatanan pertama, namun juga mengandung kedua bagian tanda 
denotatif yang melandasi keberadaanya.

Kemudian Barthes juga menyertakan aspek mitos. Aspek mitos yakni di mana ketika aspek konotasi menjadi pemikiran populer di masyarakat. Maka mitos telah terbentuk terhadap tanda tersebut. Pemikiran Barthes inilah yang dianggap paling operasional sehingga sering digunakan dalam penelitian. Sobur (2013: 17) menjelaskan bahwa di dalam mitos juga terdapat pola tiga dimensi, yakni penanda, petanda, dan tanda. Namun sebagai sistem yang unik, mitos dibangun oleh suatu rantai pemaknaan yang telah ada sebelumnya, atau dengan kata lain mitos disebutkan dengan suatu sistem pemaknaan pada tataran kedua.

\section{Persepsi}

Di dalam kehidupan sehari-hari manusia selalu berhadapan dengan berbagai rangsangan (stimulus), baik yang menyangkut dirinya sendiri sebagai makhluk individu, ataupun sebagai makhluk sosial. Rangsangan ini dapat berupa rangsangan fisik maupun non fisik. Reaksi terhadap suatu rangsangan berbedabeda antara satu manusia, dengan manusia lain. hal ini disebabkan karena manusia secara individu berbeda-beda. (https:// www.google.com/amp/s / datakata. wordpress.com/2015/01/17/definisipersepsi/amp/)

Menurut Kamus Besar Bahasa Indonesia (1995), persepsi adalah tanggapan penerimaan langsung dari sesuatu, atau merupakan proses seseorang mengetahui beberapa hal melalui panca inderanya (http://kbbi.web.id/persepsi). Menurut Gibson (1996: 134), persepsi adalah proses untuk memahami lingkungannya, meliputi objek, orang, simbol, atau tanda yang melibatkan proses kognitif (pengenalan). Proses kognitif adalah proses di mana individu memberikan arti melalui penafsirannya terhadap rangsangan (stimulus).

Selaras dengan pengertian persepsi di atas, Irwanto (2002: 71) membagi persepsi dalam dua macam, yakni persepsi positif (berkenaan dengan upaya pemanfaatan, baik tahu tidaknya ataupun kenal tidaknya) dan persepsi negatif (berkenaan dengan ketidakselarasan dari awal, tahu tidaknya ataupun kenal tidaknya).

\section{Tato}

Tato merupakan salah satu warisan kebudayaan yang sudah ada sejak zaman sebelum Masehi. Menurut Nicholas (Olong, 2006:83-84) menjelaskan bahwa kata tato yang berasal dari kata tatau, dibawa oleh Josep Banks yang berlabuh pada tahun 1969 di Tahiti.

Maka dari itu kata tato berasal dari bahasa Tahiti, "tatu" yang berarti tanda atau menandakan sesuatu. Menurut Kamus Besar Bahasa Indonesia tato adalah gambar (lukisan) pada kulit tubuh (http://kbbi. web.id/tato). Sedangkan menato adalah melukis pada kulit tubuh dengan cara menusuki kulit dengan jarum halus yang sudah dimasuki zat pewarna (Daryanto, 1998: 551). Dalam proses menato akan menghasilkan penandaan dalam tubuh.

Dalam hal penandaan di dalam tubuh, Turner (Olong, 2006:85) membagi dua macam teknik penandaan, yaitu: pertama, scarification. Kedua, cicatrization. Penandaan pertama menunjukkan teknik penandaan 
dengan cara menggoreskan sehingga menimbulkan beberapa luka di permukaan tubuh. Sedangkan penandaan kedua, dilakukan dengan cara menyobek kulit dan menyumpalkan sesuatu barang ke dalam kulit tersebut. Sehingga dapat membentuk sebuah motif tato yang mempunyai makna dengan gaya visual tertentu.

\section{Youtube}

Youtube adalah sebuah situs web video sharing (berbagi video) yang populer di mana para pengguna dapat memuat, menonton, dan berbagi klip video secara gratis. Didirikan pada bulan Februari 2005 oleh 3 (tiga) orang mantan karyawan Paypal, yaitu Chad Hurley, Steve Chen, dan Jawed Karim. Umumnya video-video di youtube adalah video klip, film, TV, serta video buatan para penggunanya sendiri (Fatty, Nadjib, dan Andi, 2016:2).

Youtube menjadi situs online video provider paling dominan di Amerika Serikat, bahkan dunia. Dengan menguasai 43\% pasar dan diperkirakan 20 jam durasi video di upload ke youtube, setiap menitnya dengan 6 (enam) miliar views per hari (Fatty, Nadjib, dan Andi, 2016). Melihat persentase tersebut, Deddy Corbuzier melihat peluang di dunia digital yang semakin berkembang. Deddy semakin dikenal berkat kontenkonten podcast-nya, yang menghadirkan orang-orang dari berbagai kalangan, termasuk Hendric Shinigami yang berprofesi sebagai pembuat/pekerja tato, sekaligus orang yang bertato.

\section{Analisis Semiotika Roland Barthes tentang Persepsi Tato pada Channel Youtube Podcast Deddy Corbuzier Bersama Hendric Shinigami Tayangan}

\section{Januari 2020}

Roland Barthes menjelaskan bahwa situasi pemaknaan yang datang tiba-tiba, di bawa oleh simbol yang 'dilihat oleh mata' (denotasi) kemudian 'ditafsirkan oleh akal' (konotasi), inilah yang dinamakan tahap (two order of signification). Ketika konotasi menjadi pemikiran populer di masyarakat, maka mitos terbentuk atas penandaan tersebut. Mitos sendiri mempunyai arti meyakinkan orang untuk melakukan/ tertarik pada sesuatu.

Dengan teori Roland Barthes di atas, terdapat makna denotasi, konotasi, dan mitos pada persepsi tato dalam channel youtube podcast yang dipublikasikan pada 25 Januari 2020 dengan durasi 26 menit 7 detik, sebagai berikut:

Pertama, makna denotasi. Makna denotasi adalah makna sebenarnya atau asli. Makna tersebut di dapat dari aspek psikologis, seperti perasaan, emosi, atau keyakinan dengan budaya, pengetahuan, sampai sejarah (Juprinedi, Uly, dan Miranto, 2020:2). Tato dalam makna sebenarnya atau asli adalah gambar (lukisan) pada tubuh seseorang, hal ini di dapat dalam hal pengetahuan. Bahkan tato juga menjadi keyakinan budaya pada suku-suku tertentu, dengan alasan masingmasing, ada yang hanya menjadi identitas, ada yang menjadikan tato sebagai simbol kawan atau lawan saat berperang, ada juga yang menggunakan tato sebagai wujud karya seni yang indah. 
Kedua, makna konotasi. Makna konotasi adalah makna yang timbul dari sikap prbadi, sosial, dan kriteria tambahan yang dikenakan dengan makna konseptual. Makna-makna konotatif sifatnya lebih profesional dan operasional. Dengan kata lain, makna konotatif adalah makna yang dikaitkan dengan situasi dan kondisi tertentu. Atau juga bisa diartikan sebagai makna tambahan dan adanya penafsiran.

Menurut Chaer dalam (Nina Selviana, 2018:1) mengatakan bahwa sebuah kata atau persepsi dikategorikan makna konotatif apabila mempunyai "nilai rasa", baik positif ataupun negatif. Dalam memberikan sebuah makna pada tato atau orang yang bertato, seringkali pemaknaanya identik dengan orang yang brandal, brengsek, pengguna narkoba, dan sisi negatif lainnya. Hal itu sudah menjadi stigma di tengahtengah masyarakat luas.

Ketiga, mitos. Mitos Roland Barthes muncul dikarenakan persepsi dari Roland sendiri bahwa dibalik tanda-tanda, terdapat makna yang misterius, yang akhirnya melahirkan sebuah mitos. Jadi, mitos-mitos yang dimaksud berkaitan dengan tandatanda dalam komunikasi sehari-hari, baik melalui ucapan atau tertulis. Sehingga makna dari mitos bersifat melampaui fungsi dan bentuk (Asrofah, 2014:2).

Tato jika dilihat dari arti bermakna gambar (lukisan) pada tubuh seseorang "makna denotatif", tiba-tiba pada tataran "makna konotatif" memaknai tato sebagai bentuk/sisi negative, hal ini dikarenakan adanya bangunan persepsi yang menunjukkan pada masyarakat umum, bangunan persepsi tersebut di dapat pada ranah media, cerita-cerita di

60 |Jurnal An-Nida, Vol. 12, No. 1, Januari-Juni 2020 lingkup masyarakat, atau adanya proyeksi orang bertato yang selalu melakukan halhal negatif. Akan tetapi, sangat tidak adil ketika pemaknaan tato selalu di-image-kan negatif. Sebab, tidak semua orang yang bertato itujahat, negatif, danlain sebagainya. Jika dilihat dari makna mitos, kejahatan, brandal, negatif, dan lain sebaginya tidak ada hubungannya dengan tato.

\section{Persepsi Tato dari Hendric Shinigami,} Deddy Corbuzier, dan Warganet/Netizen pada Channel Youtube Podcast Deddy Corbuzier Bersama Hendric Shinigami Tayangan Januari 2020

Terdapat 3 persepsi tato dari perspektif Hendric Shinigami, Deddy Corbuzier, dan warganet atau netizen, dalam channel youtube podcast Deddy Corbuzier versi "Raja Tatto Gue Ajak Debat" dalam memberi pemahaman terhadap masyarakat luas, sebagai berikut:

1. Persepsi Tato dari Hendric Shinigami selaku narasumber dan proyeksi tato/ orang bertato

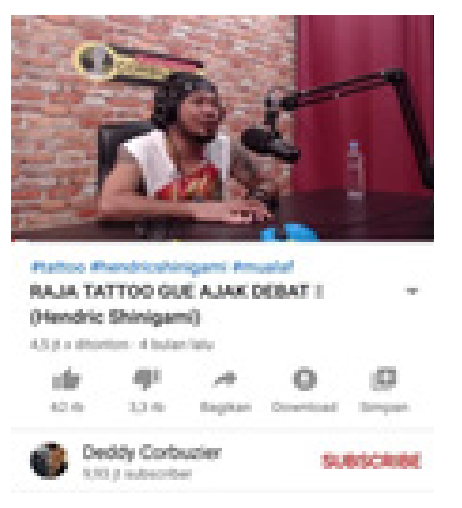

Gambar 1. Hendric Shinigami saat menjadi narasumber

Pada menit 10:25 Hendric ditanya oleh Deddy Corbuzier tentang orang yang memiliki tato. 
Deddy : Menurut elu, orang bertato itu termasuk dalam golongan brandal, brengsek atau yang lainya nggak sih?

Hendric : Saya kurang setuju kalo ada anggapan seperti itu, karena orang yang bertato itu belum tentu brandal. Tato tidak bisa menggambarkan karakter seseorang.

Pada menit 14:46 Hendric ditanya Deddy tentang pelanggan.

Deddy : Kalo mau nato di tempat elu harus nunggu berapa lama?

Hendric : Sekitar 1 tahun hehe

Deddy : Widiiih, lama banget ya. Kirakira ada pelanggan yang ngeselin nggak?

Hendric : Pasti ada, ada kriteria yang harus dipenuhi agar aku mau melayani dia. Pertama, ketika ada orang yang sombong, bertingkah seenaknya dengan merasa bahwa dirinya punya uang. Kedua, ketika akan masuk studio saya, harus lepas sendal/sepatu". Tradisi ini sudah saya pertahankan hampir 10 tahun.

Pada menit 23:38, Hendric Shinigami menjelaskan bahwa orang bertato sepertinya juga bisa melakukan hal positif, seperti rutin mengadakan Bakti Sosial".

Deddy : Sebelum saya tutup podcast ini, saya ingin bertanya satu kali lagi, apakah orang bertato selalu brandal, brengsek, dan bajingan?

Hendric : Tidak semua. Saya tidak memungkiri kalo emang ada orang yang bertato dan dia brengsek, brandal, dan sebagainya. Akan tetapi, orang bertato tidak selalu negatif, buktinya saya. Saya rutin mengadakan bakti Sosial.

Melihat penyampaian Hendric Shinigami narasumber terkait tato dalam konten youtube Deddy Corbuzier versi
“Raja Tatto Gue Ajak Debat" dalam mempersepsikan tato dapat diambil dari dua poin, yaitu: (1) Seseorang yang bertato, tidak semua brandal, karena tato tidak dapat menggambarkan sifat seseorang. (2) Hendric Shinigami dalam memproyeksikan dirinya, selalu memegang prinsip sopansantun dan etika yang baik, serta rutin dalam mengadakan Bakti Sosial.

2. Persepsi Tato dari Deddy Corbuzier selaku host dan pemilik akun channel youtube podcast

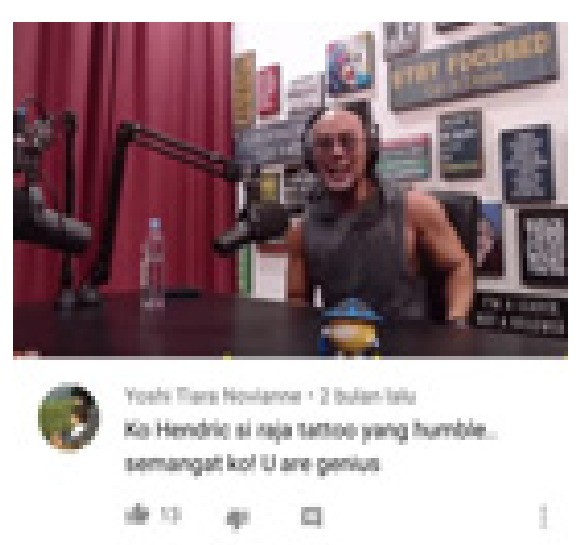

Gambar 2. Dedy Corbuzier saat menjadi host dan pemilik Channel Youtube podcast.

Pada menit 19:32, Deddy mengatakan, "Mengenal orangnya, baru menilai".

Deddy : Kamu bertato sejak kapan?

Hendric : Sejak SMP

Deddy : Lah kok nggak ketahuan gurunya?

Hendric : Tatoku di bagian pergelangan kaki, jadi ketutup kaos kaki.

Deddy : Temen-temenmu nggak ada yang tau? Tetangga?

Hendric : Nah ini, ada cerita pas aku umur-umur itu. Temen-temen yang biasa bermain sama aku, lama-kelamaan menghilang karena tidak diperbolehkan oleh orang tuanya. Dikira aku yang bertato ini dianggap anak nakal dan lain 
sebagainya.

Deddy : Iya yah. Stigma itu emang sudah lama ada. Cuma menurut saya, stigma itu kurang benar. Banyak kok tementemenku yang bertato, dan dia baik. Jadi kalo bisa kenal orangnya dulu, baru menilai.

Pada menit ke 22:23, Deddy mengatakan, "Setiap orang memiliki sisi positif. Jadi, paradigma orang yang bertato selalu identik dengan negatif, harus dirubah".

Deddy : Gimana kabarnya tetanggamu, setelah melihat kamu sukses?

Hendric : Itu dia. Aku kayak dibanggabanggain sekarang. Padahal dulunya bisa dikatakan dibenci.

Deddy : Nah, maka dari itu harus merubah paradigma orang bertato selalu identik dengan negatif. Karena setiap orang memiliki sisi positif.

Deddy melihat dari dua perspektif. (1) Kenal orangnya dulu, baru menilai. (2) Setiap orang pasti memiliki sisi positif. Hal ini menunjukkan bahwa Deddy berharap agar anggapan atau paradigma negatif pada tato maupun orang yang bertato dihilangkan. Seperti kata-kata Deddy, mengenal dulu, baru menilai secara tidak langsung mempraktikkan salah satu cara agar terhindar dari kesalahan komunikasi. Sedangkan dengan melihat setiap orang memiliki sisi positif, akan berimbas pada prasangka baik. Hal itu sangat dianjurkan dalam Islam.

3. Persepsi tato dari warganet/netizen, peneliti mengambil tiga netizen yang dijadikan sample, dalam mempersepsikan tato dengan cara menulis di kolom komentar pada channel youtube podcast Deddy
Corbuzier versi “Raja Tatto Gue Ajak Debat", sebagai berikut:

a. misteriyadi_ ia tidak sepaham ketika orang yang bertato dipersepsikan brengsek, ia berkomentar "koruptor tidak tattoan, tapi brengsek. So Open Your Eyes." Dari tulisan tersebut, selaras dengan ungkapan, "don't judge to the cover". Belum tentu orang yang tidak tattoan itu baik, dan orang yang bertato itu buruk.

b. Yoshi Tiara Novianna mempersepsikan tato dengan melihat Hendric yang humble. Artinya, Yoshi tidak serta merta menghakimi bahwa orang bertato selalu negatif.

c. Zul Nain95, ia dalam mempersepsikan tato, dilihat dari perspektif agama Islam yang menyatakan bahwa membuat tato pada tubuh hukumnya haram (hukum Islam yang berarti larangan). Akan tetapi, ia menambahi dengan steatment "Bagi yang terlanjur jangan diterusin, cukup bertaubat".

Dari paparan ketiga persepsi tentang tato, baik dari Hendric Shinigami, Deddy Corbuzier, dan warganet/netizen, tato atau orang bertato sangat tidak adil ketika dianggap negatif. Sebab, orang yang bertato belum tentu buruk, begitu juga sebaliknya orang yang tidak bertato belum tentu baik. Akan lebih bijaksana ketika jangan terburu-buru dalam memaknai sesuatu, jika objeknya orang maka kenali dulu secara mendalam, baru menilai sosok orang tersebut. 


\section{SIMPULAN}

Berdasarkan pembahasan yang telah peneliti lakukan dengan menggunakan metode semiotika Roland Barthes, yakni denotasi, konotasi, dan mitos, maka peneliti dapat menarik kesimpulan bahwa:

Pertama, terdapat makna denotasi, konotasi, dan mitos. Makna denotasi: tato adalah gambar (lukisan) pada tubuh seseorang. Makna konotasi: tato identik dengan orang yang brandal, brengsek, pengguna narkoba, dan sisi negatif lainnya. Mitos: tato dan image negatif tidak ada hubungannya.

Kedua, Hendric, Deddy, dan warganet atau netizen dalam mempersepsikan tato, sebagai upaya untuk memberi pemahaman terhadap masyarakat umum sebagai berikut: (1) Hendric Shinigami: Tato tidak bisa menggambarkan sifat seseorang; Orang yang bertato juga mempunyai etika atau sopan-santun; dan orang bertato juga bisa melakukan kegiatan positif, dalam hal Bakti Sosial. (2) Deddy Corbuzier: Setiap orang pasti mempunyai sisi positif, begitu juga pada orang bertato; Mengenal orangnya 'orang bertato atau tidak', baru menilai. (3) Warganet atau netizen: Koruptor tidak tattoan, tapi brengsek. Artinya, brengsek tidak selalu disematkan kepada orang bertato; Hendric Shinigami tattoan tapi humble. Artinya, ada sisi positif yang dapat dilihat dari orang bertato; Bagi yang terlanjur tatoan jangan diterusin, cukup dengan bertaubat.

\section{Implikasi dan Keterbatasan Penelitian}

Peneliti menemukan sebuah persepsi tentang tato. Persepsi dibatasi dalam wilayah media youtube pada channel youtube podcast milik Deddy Corbuzier. Dengan adanya kesimpulan bahwa persepsi tentang tato yang identik dengan negatif hanyalah mitos, jika mengambil dari teori semiotika Roland Barthes. Ditambah satu lagi, orang bertato atau tidak, secara mutlak tidak bisa dijadikan pedoman dalam mempersepsikan baik atu buruk. Lihat sisi positif dan kenali lebih dulu, baru membentuk sebuah persepsi.

Semoga pada penelitian mendatang, yang membahas terkait persepsi ataupun tato, bahkan analisis semiotika Roland Barthes, cakupannya bisa diperluas, agar masyarakat lebih paham porsi dari persepsi itu sendiri. 


\section{DAFTAR PUSTAKA}

\section{Buku/karangan ilmiah:}

Anggraini, Lia dan Kirana Nathalia. (2018). Warna-warni DKV. Bandung: Penerbit Nuansa.

Budiman, Kris. (2011). Semiotika Visual. Yogyakarta: Penerbit Buku Baik.

Daryanto. (1998). Kamus Lengkap Bahasa Indonesia. Surabaya: Apollo Lestari.

Gibson, James L. (1996). Organisasi: Perilaku, Struktur, dan Proses, diterjemahkan oleh Ninuk Andriani, Jakarta: Binarupa Aksara.

Irwanto. (2020). Psikologi Umum. Jakarta: PT Prenhallindo.

Kriyantono, Rachmat. (2007). Teknik Praktis Riset Komunikasi. Jakarta: Kencana.

Olong, Hatib Abdul Kadir. (2006). Tato. Yogyakarta: LKiS Pelangi Aksara.

Rahman, Abdul. (2005). Pendidikan Agama dan Pengembangan untuk Bangsa. Jakarta: PT. Raja Grafindo Persada.

Sobur, Alex. (2016) Semiotika Komunikasi. Bandung: PT Remaja Rosdakarya.

\section{Jurnal ilmiah:}

Asrofah. (2014). Semiotik Mitos Roland Barthes dalam Analisis Iklan di Media Massa. Jurnal Sasindo, Vol 2 No 1.

Cecariyani, Shera Aske dan Gregorius Genep Sukendro. (2018). Analisis Strategi Kreatif dan Tujuan Konten Youtube (Studi Kasus Konten prank Yudhist Ardhana). Jurnal Prologia, Vol 2 No 2.

David, Sondakh, dan Harilama. (2017). Pengaruh Konten Vlog dalam Youtube terhadap Pembentukan
Sikap Mahasiswa Ilmu Komunikasi Fakultas Ilmu Sosial dan Politik Universitas Sam Ratulangi. Acta Diurna, Vol 4 No 1.

Fadilah, Yudhapramesti, dan Aristi. (2017). Podcast sebagai Alternatif Distribusi Konten Audio. Kajian Jurnalisme, Vol 1 No 1.

Faiqah, Fatty, Muh. Nadjib, dan Andi Subhan Amir. (2016). Youtube Sebagai Sarana Komunikasi Bagi Komunitas Makassarvidgram. Jurnal Komunikasi KAREBA, Vol 5 No 2.

Juprinedi, Uly, dan Miranto. (2020). Analisis Makna Denotatif dan Konotatif dalam Film Upin \& Ipin Episode Kenangan Mengusik Jiwa. Journal of Digital Education, Communication, and Arts, Vol 3 No 1.

Listyarini dan Sarifah. (2020). Analisis Dieksis Dalam Percakapan Pada Channel Youtube Podcast Deddy Corbuzier Bersama Menteri Kesehatan tayangan Maret 2020. Jurnal Pendidikan Bahasa dan Sastra Indonesia, Vol 9 No 1.

Noviyanto, Leonardus Ristiardi. (2013). Persepsi Masyarakat Terhadap Perempuan Bertato. Skirpsi Universitas Pembangunan Nasional"Veteran" Jawa Timur.

Nugraha, Adhitiya. (2016). Fenomena Komunikasi Remaja Perempuan Bertato Di Pekanbaru, Jurnal JOM FISIP, Vol 3, No 2.

Selviana, Nina. (2018). Makna Denotasi dan Konotasi pada Ungkapan Tradisional dalam Konteks Pernikahan Adat Suku Pamona. Jurnal Bahasa dan Sastra, Vol 3 No 2. 
Umbara, Suciptawati, dan Nilakusumawati. (2018). Pengaruh Seni dan Sosial Budaya Terhadap Persepsi Masyarakat Mengenai Tato Menggunakan Structural Equation Modeling (SEM). E-Jurnal Matematika, Vol 7 No 4.

\section{Internet:}

Kamus Besar Bahasa Indonesia (KBBI). (1995). Pengertian Persepsi. http://kbbi.web.id/persepsi.html. Diunduh pada 27 Juni 2020.

Kamus Besar Bahasa Indonesia (KBBI). (1995). Pengertian Persepsi. http:// kbbi.web.id/tato.html. Diunduh pada 27 Juni 2020.

MyNote. (2015). Definisi Persepsi. My World. Datakata.wordpress. com. https://www.google.com/ amp / s / datakata.wordpress. com/2015/01/17/definisi-persepsi/ amp/. Diunduh pada 27 Juni 2020. 